\title{
A EXPRESSÃO DO SUJEITO NULO EM REDAÇÕES DE ALUNOS DO ENSINO FUNDAMENTAL
}

\author{
Josilene de Jesus Mendonça \\ Jaqueline dos Santos Nascimento
}

\begin{abstract}
RESUMO
O português brasileiro permite o não preenchimento da posição sujeito; no entanto, estudos linguísticos têm constatado uma tendência ao uso do sujeito expresso. Nesse sentido, visamos analisar o uso do sujeito nulo em produçôes escritas de estudantes do ensino fundamental. Após análise, constatamos que existe variação entre sujeito nulo e expresso, sendo as variáveis linguísticas significativas para a compreensão do fenômeno.
\end{abstract}

PALAVRAS-CHAVE: preenchimento do sujeito; escrita escolar; sociolinguística.

\section{Introdução}

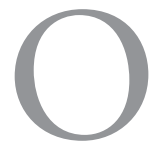

português brasileiro $(\mathrm{PB})$ é uma língua que permite o não preenchimento da posição sujeito. Porém, conforme vem sendo atestado em pesquisas sociolinguísticas (DUARTE, 1993; DUARTE et al., 2012; SOUZA \& SACHET, 2008; SANTOS, 2009; SANTOS, 2014; SILVA 2007, entre outros), a expressão do sujeito no PB tem passado por mudanças apresentando uma tendência à utilizaçáo do preenchimento. A pesquisa realizada por Duarte (1993), por exemplo, nos mostra que a forma náo marcada do sujeito pronominal consiste na forma plena, a mais frequente, já o sujeito nulo é a forma marcada, isto é, a menos frequente; fato contrário ao que mostram os resultados do português europeu oral. 
Nesse sentido, tomando como base os pressupostos teóricos e metodológicos da Sociolinguística Variacionista (LABOV, 2008) e, como componente gramatical, alguns pressupostos da teoria de Princípios e Parâmetros, objetivamos analisar o uso do sujeito nulo na escrita de estudantes do Ensino Fundamental, a fim de verificar se a tendência apontada por Duarte (1993) é confirmada no âmbito escolar, tendo em vista que a escola adota uma postura normativista, ensinando o sujeito oculto como opção prototípica. Além disso, acreditamos que a modalidade escrita da língua sofre maior influência da perspectiva normatizadora do ensino. Partimos da hipótese de que o não preenchimento será favorecido na escrita dos estudantes, visto que esta modalidade da língua é mais monitorada.

Feita esta breve introdução, passamos à organização do artigo. Na segunda seção, serão apresentadas algumas consideraçooes teóricas referentes ao preenchimento do sujeito. Em seguida, detalharemos a metodologia utilizada nesta pesquisa. $\mathrm{Na}$ seção seguinte, serão expostos e discutidos os resultados. E por fim, serão feitas algumas consideraçôes a respeito do estudo realizado.

\section{O sujeito nulo}

A variação do preenchimento do sujeito se enquadra em um dos parâmetros postulados na literatura gerativa (CHOMSKY, 1981): o parâmetro do sujeito nulo, que consiste na possibilidade de uma língua apresentar ou não pronomes nulos na posição de sujeito.

Dessa forma, de acordo com esse parâmetro, é possível dizer que há dois tipos de língua: as de sujeito pleno e as de sujeito nulo. Nas línguas de sujeito pleno não é permitido uma categoria vazia na posição de sujeito, ou seja, os falantes necessitam obrigatoriamente preencher todos os sujeitos pronominais, independentemente do tipo de verbo que acompanham ou das condiçóes em que apareçam.

Já nas línguas de sujeito nulo, é permitido que o falante não use explicitamente o sujeito pronominal; exceto nos casos de ênfase ou contraste, em que o sujeito preenchido é utilizado como recurso expressivo. As frases sem sujeito, porém, podem ser perfeitamente compreendidas, uma vez que o sujeito será licenciado por alguma outra informaçáo que esteja disponível aos falantes; a desinência do verbo ou o contexto, por exemplo, podem identificar a que pessoa do discurso a sentença se refere. 
O sistema linguístico do português brasileiro permite o não preenchimento da posição de sujeito, sendo o referente compreendido a partir de informaçôes disponíveis para identificação da pessoa do discurso (VILLARINHO, 2006, p. 3). Porém, estudos linguísticos têm constatado uma preferência pelo preenchimento, sugerindo uma mudança em curso na marcação do valor do parâmetro do sujeito nulo de [+ sujeito nulo] para [- sujeito nulo].

Dentre os trabalhos que atestem tal fato, podemos citar o trabalho pioneiro de Duarte (1993), que investigou a utilização de sujeitos em sete peças de teatro populares escritas no período de 1845 a 1992. A partir desse estudo diacrônico, a autora verificou uma redução na utilização de sujeitos nulos, e atribuiu o aumento da utilizaçáo de sujeitos plenos a uma impossibilidade de se identificar os nulos pelas desinências verbais, uma vez que houve, em decorrência de alteraçooes no sistema pronominal, uma mudança no paradigma flexional do PB.

Em relação aos paradigmas verbais, a autora destaca em sua pesquisa três períodos distintos. No primeiro período, o paradigma analisado possuía seis formas de flexão verbal, tais formas se reduziram para quatro, marcando o segundo período. Conforme Duarte (1993), a transição teria se iniciado com a substituição da forma da segunda pessoa pronominal singular tu e a segunda pessoa plural vós pela forma você(s) que utiliza a flexão de terceira pessoa. E, mais recentemente, a primeira pessoa plural pronominal nós estaria sendo substituída pela expressão pronominal a gente.

Hipótese semelhante foi adotada por Souza et al. (2010) ao investigar a distribuição do número de sujeitos nulos e sujeitos realizados em textos escritos de alunos adolescentes do Ensino Fundamental de uma escola pública de Florianópolis. Tal estudo revelou que os pronomes que mais apresentaram o sujeito preenchido foram aqueles que fazem concordância de $3^{\mathrm{a}}$ pessoa ( $a$ gente, vocêl vocês e ele(a)l eles(as)) com destaque para a gente e vocêlvocês (PR (peso relativo $)=0,87$ e 0,85 , respectivamente); já os pronomes de $1^{\text {a }}$ pessoa, eu e nós, apresentaram menor probabilidade de uso do sujeito expresso, com pesos de 0,43 e 0,31, respectivamente. Segundo Souza et al. (2010, p. 101), o maior índice de preenchimento do sujeito na $3{ }^{a}$ pessoa decorreu da necessidade de retenção do pronome para evitar ambiguidade, dada a importância de recuperar o referente por meio de elementos de concordância, nesse caso, por desinências não distintivas. 
De acordo com Santos (2009, p. 77), o sujeito nulo é utilizado em contextos em que o referente é esperado ou mantido, ou seja, em situaçóes em que não existem elementos que possam gerar ambiguidades na compreensão do referente. Os resultados da autora demonstram que, embora haja uma tendência ao preenchimento do sujeito pronominal de $3^{\text {a }}$ pessoa, há contextos linguísticos favorecedores para a realização do sujeito nulo como, por exemplo, em situaçóes em que o referente possui uma estrutura anterior sintaticamente acessível, como mostraram Duarte (1995) e Barbosa, Duarte e Kato (2005). Nesse sentido, Santos conclui que

O PB tem um comportamento atípico no contexto das línguas românicas e que, se ainda não é uma língua negativamente marcada em relação ao parâmetro do Sujeito Nulo, tampouco é uma língua positivamente marcada em relação a ele. E se a tendência ao preenchimento do sujeito, por um lado, é confirmada, por outro, há ainda a realização do sujeito nulo, o que sugere a manifestação de um tipo particular de língua pro-drop, em que a categoria vazia é licenciada em um sistema diferente das línguas de sujeito nulo (SANTOS, 2009, p. 94-95).

Em análise do preenchimento do sujeito pronominal em edições da revista em quadrinhos Pato Donald, Silva (2007) também constatou que as variáveis linguísticas são as mais significativas para o funcionamento do fenômeno, pois seus resultados estatísticos apontaram a pessoa verbal como fator mais relevante. A autora, em análise do preenchimento/não preenchimento dos pronomes de $1^{\mathrm{a}}$ e $2^{\mathrm{a}}$ pessoa na posição de sujeito, constatou que a $1^{\mathrm{a}}$ pessoa favorece o não preenchimento, já o uso de sujeito pronominal expresso é favorecido por pronomes de $2^{\text {a }}$ pessoa. Segundo Silva (2007), tal resultado pode ser justificado pela resistência ao preenchimento do pronome nós, pois este pronome apresenta desinência número-pessoal bem marcada.

Pode-se afirmar que a mudança no paradigma pronominal e, consequentemente, no paradigma flexional no $\mathrm{PB}$ está correlacionada à mudança que se verifica na passagem de sujeito nulo para sujeito preenchido, uma vez que, à medida que o sistema pronominal se modificou, o paradigma flexional também se alterou diminuindo as desinências verbais.

Após essa breve explanação sobre o preenchimento do sujeito a partir da apresentação de alguns resultados de trabalhos realizados, na seção seguinte, será apresentada a metodologia utilizada para a realização deste estudo. 


\section{Procedimentos metodológicos}

Para a realização desse estudo utilizamos uma amostra composta por 88 textos produzidos por alunos do ensino fundamental II, do Colégio Nossa Senhora da Piedade situado na cidade de Lagarto/SE. 44 alunos participaram da coleta, sendo 18 do $6^{\circ}$ ano EF e 26 do $9^{\circ}$ ano EF. Os alunos foram estimulados a produzirem dois gêneros textuais: uma carta argumentativa e uma narrativa. A seleção desses gêneros justifica-se pela formalidade da carta argumentativa, uma vez que esta deverá ser dirigida ao diretor da escola, e do caráter mais criativo e espontâneo do texto narrativo, possibilitando-nos uma comparação do fenômeno nos dois gêneros textuais. Acreditamos que a carta argumentativa apresentará maior tendência ao uso do sujeito não preenchido, tendo em vista a formalidade do gênero.

A escolha por gêneros escritos justifica-se pela hipótese adotada de que há uma maior probabilidade de ocorrência do parâmetro [+ sujeito nulo], uma vez que, a escrita é a modalidade da língua mais conservadora.

Para a realização do nosso estudo, foi necessário seguir alguns passos. Inicialmente houve a elaboração dos instrumentos de coleta, ou seja, duas propostas de produçáo textual (proposta da carta argumentativa e a proposta da narrativa).

A proposta de produção da carta argumentativa apresenta uma situação hipotética de que a escola foi premiada pela Secretaria de Cultura com uma viagem para apenas uma turma, logo, a produção consistia na elaboração de uma carta argumentativa em nome da turma, direcionada ao diretor do colégio tentando convencê-lo de que a turma merece ser escolhida para ganhar o prêmio. A proposta de produção da narrativa apresenta um breve enunciado sobre a amizade e uma instrução para que se conte uma situação inesquecível vivida pelo aluno junto com seu(s) melhor(es) amigos(s).

Após a elaboração dos instrumentos de coleta, realizamos a coleta das redaçôes, que aconteceu em dois dias; no primeiro dia cada aluno de cada turma ( $6^{\circ}$ ano e $9^{\circ}$ ano) produziu uma narrativa em uma aula de 50 minutos, e no segundo dia cada aluno de cada turma produziu uma carta argumentativa em uma aula de 50 minutos.

Com os textos em mãos, partimos para a identificação do fenômeno: sujeito preenchido e sujeito não preenchido. Em seguida, codificamos os dados 
e fizemos o tratamento estatístico no programa Goldvarb X, e por fim fizemos a interpretação dos resultados.

\section{Não preenchimento do sujeito na escrita de alunos do EF}

O resultado geral é equilibrado, com percentual de $51,4 \%$ de sujeito não preenchido e 48,6\% de sujeito expresso, conforme podemos observar no gráfico 1 . Esse resultado confirma nossa hipótese inicial, visto que a modalidade escrita da língua é monitorada e conservadora, favorecendo, embora com pequena diferença percentual, o parâmetro [+ sujeito nulo]. No entanto, faz-se necessário notar que a diferença entre as duas opçóes de marcação da posição de sujeito sugere que o fenômeno encontra-se em variação, pois a diferença entre o preenchimento e não preenchimento é pequena. Notamos, assim, que, embora trabalhos como o de Duarte (1995) apontem uma tendência ao preenchimento, a análise da escrita escolar nos mostra que a escola age como fator de equilíbrio entre as duas opções de marcação da posição de sujeito.

Gráfico 1: Marcação da posição de sujeito em textos de estudantes do EF

Sujeito não preenchido

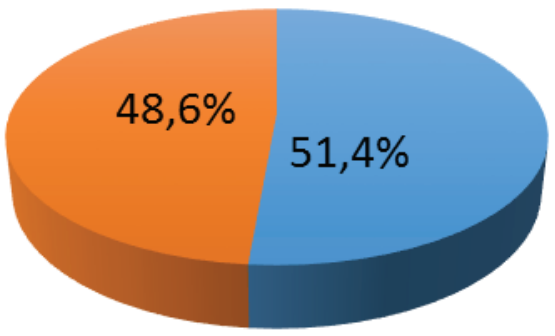

\section{sujeito preenchido}

A partir da análise dos resultados, podemos observar que a pessoa gramatical é uma variável significativa para a escolha entre o preenchimento ou não da posição de sujeito. $\mathrm{O}$ não preenchimento do sujeito é favorecido pela $1^{\text {a }}$ pessoa, com percentual de $69,5 \%$, já a $3^{\text {a }}$ pessoa propicia o uso do sujeito 
expresso, com percentual de $21,7 \%$ em função do não preenchimento, conforme podemos observar na tabela 1 .

Tabela 1. Não preenchimento do sujeito em função da pessoa gramatical

\begin{tabular}{|c|c|c|c|}
\hline & Aplicação/total & Porcentagem & Peso relativo \\
\hline $1^{\text {a }}$ pessoa & $468 / 673$ & 69,5 & 0,67 \\
\hline $3^{\text {a }}$ pessoa & $83 / 383$ & 21,7 & 0,22 \\
\hline
\end{tabular}

Os pesos relativos apresentados na tabela nos mostram que o não preenchimento do sujeito é favorecido por contextos de $1^{\text {a }}$ pessoa, com peso de 0,67 , enquanto a $3^{\text {a }}$ pessoa favorece o uso do sujeito preenchido, com peso relativo de 0,22 em função do não preenchimento. Esses resultados corroboram com os estudos de Silva (2007), Souza et al (2010) e Santos (2014), os quais também constataram que os sujeitos de $1^{\text {a }}$ pessoa favorecem o não preenchimento da posição, visto que essa pessoa gramatical apresenta desinências número-pessoal bem marcada, não gerando dificuldade na compreensão do referente. Ao contrário disso, a $3^{\text {a }}$ pessoa gramatical não possui desinências distintivas, sendo necessária a expressão do sujeito para evitar ambiguidade, visto que a flexão verbal de terceira pessoa pode associar-se aos pronomes $a$ gente, você e ele, além de poder referir-se também a formas nominais.

Assim, a baixa frequência de sujeito nulo de $3^{\text {a }}$ pessoa justifica-se dentro de um quadro de mudanças ocorridas no PB. Alterações no quadro pronominal, com a entrada dos pronomes você e a gente, e consequente redução no paradigma flexional geram a necessidade de expressão do sujeito, visto que diferentes formas pronominais, além dos sintagmas nominais, utilizam a mesma flexão verbal, ou seja, a $3^{\text {a }}$ pessoa; podendo, assim, gerar dificuldade na compreensão do referente.

Os sujeitos de segunda pessoa também foram controlados; no entanto, na amostra analisada estes se mostraram categoricamente preenchidos. Foram encontrados 15 ocorrências de sujeito de $2^{\text {a }}$ pessoa, todas com sujeito expresso. Tal resultado justifica-se pelo uso do pronome você como sujeito de $2^{\text {a }}$ pessoa; porém, acompanhado da forma verbal de $3^{\text {a }}$ pessoa, gerando a necessidade de preenchimento, a fim de evitar ambiguidades, visto que o pronome você não apresenta desinência distintiva. A seguir, apresentamos alguns exemplos 
retirados da amostra analisada, a fim de demonstrarmos os contextos de utilização do não preenchimento da posição de sujeito em relação à pessoa gramatical.

(1) Espero que você entenda nosso ponto de vista, esperamos muito que possamos curtir essa viagem juntos. $(C 9 Z)^{1}$

(2) ... por isso estou pedindo que realize o nosso sonho. (C9S)

(3) Em breve você saberá quem é a pessoa. (N6P)

A partir dos exemplos de sujeito não preenchido apresentados nos excertos (1) e (2) podemos observar que a $1^{\text {a }}$ pessoa é identificável pela desinência número-pessoal como em espero, esperamos, possamos curtir e estou. Exemplos como (2), em que a forma verbal de $3^{\text {a }}$ pessoa (realize) marca um sujeito não preenchido, nos demonstra que, apesar da $3^{a}$ pessoa gramatical favorecer o preenchimento do sujeito, evitando ambiguidades; o sujeito nulo será uma opção válida nos contextos em que o referente possa ser recuperado. Em relaçáo ao preenchimento do sujeito de $2^{\text {a }}$ pessoa, destacamos o uso do pronome você nos exemplos (1) e (3), evidenciando a necessidade de preenchimento para evitar ambiguidade.

A variável número do sujeito também se mostra relevante para a compreensão do funcionamento do fenômeno. Sujeitos no plural favorecem o uso do sujeito nulo, com percentual de $66,3 \%$ e peso relativo de 0,57 , já sujeitos no singular apresentam apenas um percentual de 38,3\% em função do não preenchimento, com peso relativo de 0,43 , conforme observamos na tabela 2 .

Tabela 2. Não preenchimento do sujeito em função do número

\begin{tabular}{|c|c|c|c|}
\hline & Aplicação/total & Porcentagem & Peso relativo \\
\hline Singular & $218 / 569$ & 38,3 & 0,43 \\
\hline Plural & $333 / 502$ & 66.3 & 0,57 \\
\hline
\end{tabular}

O número do sujeito associado à pessoa gramatical é relevante no quadro da compreensão da variação entre sujeito nulo e sujeito expresso, isso porque

1 O símbolo ao final do excerto indica a identificação do dado. A primeira letra refere-se ao gênero textual (N: narrativa; C: carta argumentativa); o número indica a série (6: $6^{\circ}$ ano do EF, 9: $9^{\circ}$ ano do EF), o último símbolo identifica o informante. 
a desinência número-pessoal é fator decisivo na escolha entre as duas possibilidades de marcação da posição de sujeito. Os resultados dessas duas variáveis corroboram com estudos anteriores, evidenciando que sujeitos na $1^{\text {a }}$ pessoa do plural favorecem o não preenchimento da posição; ao contrário disso, a flexão verbal de $3^{a}$ pessoa do singular propicia o preenchimento da posição de sujeito, conforme explicitamos anteriormente, a fim de evitar ambiguidades na compreensão do referente. Tal resultado corrobora com os apresentados em Silva, em que a autora conclui que o pronome nós apresenta resistência ao preenchimento do sujeito (SILVA, 2007, p. 192).

O controle da variável linguística tempo verbal também nos mostrou resultados relevantes para o entendimento da variação na marcação da posição de sujeito, confirmando estudos anteriores. Conforme podemos observar na tabela 3, o presente do subjuntivo, pretérito perfeito e presente do indicativo são os tempos verbais que mais favorecem o uso do sujeito nulo na amostra analisada, com pesos relativos de 0,$76 ; 0,57$ e 0,47 , respectivamente. Já os tempos pretérito imperfeito, futuro do presente e futuro do pretérito parecem favorecer o uso de sujeito expresso, com pesos de 0,29; 0,37 e 0,38, respectivamente, em função do não preenchimento.

Tabela 3. Não preenchimento do sujeito em função do tempo verbal

\begin{tabular}{|c|c|c|c|}
\hline & Aplicação/total & Porcentagem & Peso relativo \\
\hline Presente do Indicativo & $206 / 357$ & 57,7 & 0,47 \\
\hline Presente do Subjuntivo & $9 / 14$ & 64,3 & 0.76 \\
\hline Pretérito Perfeito & $273 / 511$ & 53,4 & 0,57 \\
\hline Futuro do Pretérito & $15 / 25$ & 60 & 0,38 \\
\hline Pretérito Imperfeito & $30 / 123$ & 24,4 & 0,29 \\
\hline Futuro do Presente & $18 / 41$ & 43,9 & 0,37 \\
\hline
\end{tabular}

Em nossa análise, o presente do subjuntivo se mostrou favorecedor do não preenchimento com percentual de $64,3 \%$. Tal resultado não corrobora com os apresentados em Silva (2007), pois a autora constatou que o presente do subjuntivo apresenta tendência ao preenchimento de .70 , enquanto o presente do indicativo apresenta peso de .46 , revelando uma tendência ao náo preenchimento. Segundo Silva, o presente do subjuntivo apresenta a mesma 
desinência número-pessoal para a primeira pessoa do singular, eu, para a segunda, você e para o pronome a gente (-e), a segunda pessoa do plural também tem desinência idêntica à terceira $(-\mathrm{em})$. Desta forma é previsível a tendência ao preenchimento do sujeito pronominal para evitar interpretaçóes equívocas (SILVA, 2007, p. 199).

Acreditamos que o peso de 0,76 em função do não preenchimento está atrelado ao gênero textual carta argumentativa. O presente do subjuntivo foi utilizado pelos estudantes dentro de uma cadeia discursiva em que o referente pode ser facilmente recuperado, já que se trata do diretor(a) da escola, anteriormente referenciado por meio de um vocativo, conforme observamos no exemplo (4).

(4) Cara diretora, em nome de toda a turma venho pedir que dê esse prêmio para a classe. (C9S)

O segundo tempo verbal mais favorecedor do não preenchimento do sujeito é o pretérito perfeito, seguido pelo presente do indicativo, com pesos de 0,57 e 0,47 , respectivamente. Esse resultado pode estar atrelado ao fato de esses tempos verbais apresentarem noção aspectual simples, codificando situações encerradas, no caso do pretérito perfeito, e situações simultâneas ao momento de fala, no caso do presente do indicativo; fazendo com que os informantes, estudantes do ensino fundamental, possuam maior contato com esses tempos e, consequentemente, utilize-os mais em suas produçóes escritas. Os informantes, por conhecerem e utilizarem mais esses tempos verbais, utilizam mais as desinências distintivas, não sendo necessário preencher o sujeito. Atrelado a esse fator, há também a questão de os gêneros textuais analisados propiciarem o uso desses tempos verbais, já que o pretérito perfeito é característico das narrativas e, as cartas argumentativas favorecem o uso do presente do indicativo. Os excertos (5) e (6) exemplificam o uso desses tempos dentro da amostra.

(5) Lembro como se fosse hoje, o dia em que fui com minha amiga Kamila para a festa em comemoração a cidade. (N9S)

(6) ... nunca pensei que seria algo tão mágico ... (N9U)

O pretérito imperfeito, o futuro do presente e o futuro do pretérito são os tempos verbais que menos propiciam o uso do sujeito nulo na amostra, com 
pesos de 0,29; 0,37 e 0,38, nessa ordem. Segundo Souza \& Sachet (2008), o pretérito imperfeito tende ao sincretismo, por isso a tendência ao preenchimento é maior, a fim de evitar interpretaçóes equivocadas do referente (SOUZA \& SACHET, 2008, p. 8). Resultados semelhantes também foram apontados em Silva (2007, p. 198), em que a autora constatou tendência ao preenchimento de .79 para o futuro do pretérito e .83 para o pretérito imperfeito. Em relação ao futuro do presente, acreditamos que a pouca recorrência desse tempo verbal, faz com que o preenchimento seja favorecido, pois os informantes, por não se sentirem familiarizados com a forma verbal, sentem a necessidade de preencher o sujeito. A seguir apresentamos ocorrências desses tempos verbais na amostra.

(7) Dançávamos como vagalumes, alguns pulando, outros rolando na areia e colidindo com o mar. (N9W)

(8) Bom minhas melhores amigas são meu porto seguro, não seria nada sem elas, com elas passei momentos incriveis, nunca irei esquecer. (N96)

(9) Eu amu elas e vou sentir muitas saudades dessas doidinhas porque se um dia vou poder dizer que tive amigos incriveis é por causa delas. (N95)

A variável pragmática tipo de texto nos revelou que as cartas argumentativas favorecem o uso do sujeito nulo, com percentual de $60,2 \%$ e peso relativo de 0,57 . As narrativas apresentaram porcentagem de $46 \%$ e peso de 0,45 em função do não preenchimento, demonstrando leve tendência ao preenchimento, conforme podemos notar na tabela 4.

Tabela 4. Não preenchimento do sujeito em funçáo do tipo de texto

\begin{tabular}{|c|c|c|c|}
\hline & Aplicação/total & Porcentagem & Peso relativo \\
\hline Carta & $248 / 412$ & 60,2 & 0,57 \\
\hline Narrativa & $303 / 659$ & 46 & 0,45 \\
\hline
\end{tabular}

A tendência ao não preenchimento apresentada pelas cartas argumentativas, conforme hipótese inicial, pode ter relação com a formalidade do gênero, isto é, por ser um texto destinado ao diretor (a) e com finalidades de convencimento, a forma prototípica foi mais utilizada pelos estudantes, ou seja, o sujeito não preenchido. 
Em relação à variável social série, constatamos que o $9^{\circ}$ ano utiliza mais o sujeito nulo, com percentual de $57,5 \%$ e peso relativo de 0,58 , conforme podemos observar na tabela 5 . O sujeito preenchido é mais utilizado pelos informantes do $6^{\circ}$ ano, já que os informantes desse nível de escolaridade apresentaram peso de 0,34 em função do não preenchimento. Esses pesos relativos evidenciam que o maior tempo de exposição à escrita, alunos do $9^{\circ}$ ano, favorece o uso do sujeito nulo; ao passo que alunos de séries iniciais, $6^{\circ}$ ano, tendem a transpor a gramática da fala para suas produçóes escritas, favorecendo o uso da variante mais inovadora - sujeito preenchido. Esse resultado corrobora com os apresentados em Santos (2014), em que a autora constatou que o preenchimento do sujeito é mais frequente no início do ensino fundamental com peso .60 (SANTOS, 2014, p. 12).

Tabela 5. Não preenchimento do sujeito em função da série

\begin{tabular}{|c|c|c|c|}
\hline & Aplicação/total & Porcentagem & Peso relativo \\
\hline $9^{\circ}$ ano & $404 / 702$ & 57,5 & 0,58 \\
\hline $6^{\circ}$ ano & $147 / 369$ & 39,8 & 0,34 \\
\hline
\end{tabular}

Os resultados demonstram também que os informantes do sexo feminino utilizam mais o sujeito não preenchido com percentual de $60,9 \%$ e peso de 0,59 . Já os estudantes do sexo masculino apresentaram uma leve tendência ao uso do sujeito expresso, com percentual de $43,4 \%$ e peso de 0,41 em função do não preenchimento, conforme podemos notar na tabela 6 . Esse resultado pode estar atrelado à tendência de as mulheres preservarem os padróes; logo utilizam mais a forma mais conservadora da língua, o sujeito não preenchido.

Tabela 6. Não preenchimento do sujeito em função do sexo/gênero

\begin{tabular}{|c|c|c|c|}
\hline & Aplicação/total & Porcentagem & Peso relativo \\
\hline Feminino & $299 / 491$ & 60,9 & 0,59 \\
\hline Masculino & $252 / 580$ & 43,4 & 0,41 \\
\hline
\end{tabular}

Após análise dos dados, constatamos maior frequência de sujeito nulo na amostra analisada, demonstrando que há variação entre o preenchimento 
e não preenchimento da posição de sujeito. Além disso, pudemos constatar também que as variáveis linguísticas são significativas na escolha entre as duas opçóes de marcação da posição de sujeito, evidenciando que o fenômeno não é avaliado socialmente. Notamos ainda que as variantes linguísticas $1^{\text {a }}$ pessoa, plural e os tempos verbais presente do subjuntivo, pretérito perfeito e presente do indicativo favorecem o não preenchimento do sujeito. Em relação à variável pragmática analisada, observamos que o sujeito nulo é mais recorrente no gênero carta argumentativa, devido ao nível de formalidade exigido por esse gênero. Por fim, a análise das variáveis sociais nos mostrou que o não preenchimento do sujeito é mais frequente nas produções dos informantes do $9^{\circ}$ ano do ensino fundamental, evidenciando a influência da escola; e do sexo feminino.

\section{Considerações}

A investigação aqui desenvolvida teve como objetivo analisar o uso do sujeito nulo em produçôes escritas de estudantes do ensino fundamental, a fim de analisar as variáveis linguísticas (pessoa gramatical, número, tempo verbal), sociais (série; sexo/gênero) e pragmática (tipo de texto) que influenciam o uso do não preenchimento da posição de sujeito. Após análise dos dados, constatamos que o sujeito não preenchido é utilizado em contextos linguísticos específicos e que a escola exerce uma influência no que se refere ao parâmetro [+ sujeito nulo], pois age como fator de equilíbrio entre as duas opções de marcação da posição de sujeito, sendo o náo preenchimento favorecido na escrita dos alunos do $9^{\circ}$ ano.

Apesar de as categorias sociais demonstrarem que os informantes do sexo feminino e estudantes do $9^{\circ}$ ano tendem a fazer maior uso do não preenchimento e, a categoria pragmática evidenciar que as cartas argumentativas constituem contexto de favorecimento do sujeito nulo; podemos concluir, a partir dos resultados, que o funcionamento da marcação da posição de sujeito está atrelado diretamente às variáveis linguísticas, principalmente, pessoa e tempo verbal. Isso porque a diferença entre os pesos relativos nos demonstra claramente que a $1^{\text {a }}$ pessoa favorece o náo preenchimento, com peso de 0,67 , enquanto a $3^{\mathrm{a}}$ favorece o uso de sujeito expresso, com peso de 0,22 em função do não preenchimento. $\mathrm{O}$ mesmo ocorre com os tempos verbais, em que; desconsiderando o peso do presente do subjuntivo que parece ter uma relação específica com a amostra analisada, conforme já explicitamos na seção anterior; a diferença entre 
os pesos do pretérito perfeito e pretérito imperfeito nos demonstra que aquele favorece o não preenchimento com peso de 0,57 , e este favorece o uso de sujeito expresso com peso de 0,29 em função do não preenchimento.

Assim, podemos concluir que o fenômeno não é avaliado socialmente, já que as variáveis sociais não apresentam grandes diferenças entre as categorias selecionadas para análise. Além disso, constatamos que o não preenchimento do sujeito ainda é uma opção natural na escrita de estudantes do ensino fundamental, demonstrando que o sujeito expresso é utilizado em contextos linguísticos em que pode ser gerada ambiguidade na compreensão do referente como, por exemplo, em situaçóes em que a flexão verbal de $3^{\text {a }}$ pessoa aparece. Nesse sentido, faz-se necessário o trabalho em sala de aula com questôes relacionadas às ambiguidades geradas pelo uso indevido do não preenchimento do sujeito. Isto é, o professor deve demonstrar a seus alunos, por meio de situações reais de comunicação, que as duas opções de marcação da posição de sujeito são válidas no sistema linguístico do português, demonstrando, porém, que determinados contextos exigem o uso do sujeito expresso.

\section{Referências}

BARBOSA, Pilar; DUARTE, Maria Eugênia Lammoglia; KATO, Mary A. Null subjects in European and Brazilian Portuguese. Journal of Portuguese Linguistics. Universidade de Lisboa, vol. 4, p. 11-52, 2005.

CHOMSKY, Noam. Lectures on government and binding. Dordrecht: Foris, 1981.

DUARTE, Maria Eugênia Lammoglia. Do pronome nulo ao pronome pleno: a trajetória do sujeito no Português do Brasil. In: ROBERTS, I.; KATO, M. A. (Orgs.). Português Brasileiro - Uma viagem diacrônica. Campinas: UNICAMP, 1993.

A perda do princípio "evite pronome" no português brasileiro. Tese (Doutorado), Unicamp, 1995.

. O sujeito em peças de teatro (1833-1992): estudos diacrônicos. São Paulo: Parábola, 2012.

LABOV, William. Padróes sociolinguísticos. Trad. Marcos Bagno, Maria Marta Pereira Scherre e Caroline Rodrigues Cardoso. São Paulo: Parábola, 2008.

SANTOS, Ângela Marina Bravin dos. O sujeito pronominal de $3^{a}$ pessoa no português culto do Rio de Janeiro: um estudo em tempo real. D.E.L.T.A., 25:1, (67-97), 2009. 
1. SANTOS, Renata Lívia de Araújo. Um estudo variacionista sobre o preenchimento da posição do sujeito em dados de fala. Entheoria: Cadernos de Letras e Humanas. v. 1. 2014.

SILVA, Rita do Carmo Polli. Sujeito pronominal nos quadrinhos. Revista Letras, Curitiba, n. 72, p. 189-209, maio/ago. UFPR, 2007.

SOUZA, Christiane Maria Nunes de; SACHET, Patricia Floriani. Um estudo sobre o preenchimento do sujeito pronominal na fala e na escrita de jovens de Florianópolis. Anais do CELSUL, 2008.

. BRUSTOLIN, Ana Kelly Borba da Silva; SACHET, Patricia Floriani; COELHO, Izete Lehmkuhl. O preenchimento do sujeito pronominal em textos escritos de alunos adolescentes de Florianópolis. Working Papers em Linguistica (Impresso) v. esp., p. 94-107, 2010.

VILLARINHO, Clara Nóvoa Gonçalves. Sujeito Nulo no português Brasileiro: elementos para sua análise a partir de situaçóes experimentais. In.: SHEPHERD, Tania Granja e VASCONCELOS, Zinda de (Orgs.). Linguagem: teoria, análise e aplicaçóes. Rio de Janeiro: Letra Capital, 2006.

\title{
THE USE OF NULL SUBJECTS IN ELEMENTARY STUDENTS WORDINGS
}

\begin{abstract}
Brazilian Portuguese allows the omission of subject. However, linguistic studies have witnessed the use of overt subjects as a tendency. Thus, we analyzed the use of null subjects in writing among elementary students. As a conclusion, we confirmed that there is variation between both null and overt subjects, with the linguistic variables being important to the phenomenon comprehension.
\end{abstract}

KEYWORDS: subject fill; scholarly writing; sociolinguistic.

Recebido em: 31/03/2015 Aprovado em: 26/09/2015 